\title{
REDES DE INFRAESTRUTURA URBANA E SUAS RELAÇÕES COM OS COMPONENTES TÉCNICOS, SOCIAIS E AMBIENTAIS
}

\author{
URBAN INFRASTRUCTURE NETWORKS AND THEIR RELATIONSHIPS WITH \\ TECHNICAL, SOCIAL AND ENVIRONMENTAL COMPONENTS
}

\section{REDES DE INFRAESTRUCTURA URBANAY SUS RELACIONES CON LOS COMPONENTES TÉCNICOS, SOCIALESY AMBIENTALES}

\author{
Gunar Henrique Guedes * \\ gunnarguedes@gmail.com \\ Kairo Fellipe Santos Ribeiro * \\ kairomaringa@hotmail.com \\ Tânia do Carmo ** \\ taniadocarmo_@hotmail.com \\ Carlos Alberto de Oliveira Magalhães Júnior** \\ juniormagalhaes@hotmail.com
}

* Faculdade de Engenharia e Inovação Técnico Profissional, Maringá, PR - Brasil ** Universidade Estadual de Maringá, Maringá, PR - Brasil

\begin{abstract}
Resumo
O crescente desenvolvimento urbano apresenta constantemente (re)formulações que abrigam o complexo processo de estruturação física e populacional que vive em determinada cidade, caracterizando o espaço urbano, palco destas relações sociais e ambientais que fazem parte de toda a infraestrutura urbana. A base para qualquer implantação de uma nova cidade deve partir de um bom planejamento urbanístico, que leve em conta não apenas como os aspectos estruturais irão compor o novo centro urbano, mas também fatores políticos, históricos e econômicos. Neste sentido, as redes de infraestrutura urbana fazem a conexão entre todos estes aspectos que compõem a vida em sociedade. Dentre estas formas são encontradas algumas sugestões de implementações como a infraestrutura verde, que toma como aspecto relevante o ambiente natural como forma de propiciar melhores condições de vida, sendo também encontrado os processos socioespaciais, provido de segregação urbana, em que as classes menos favorecidas vão ficando isoladas em determinada região da cidade. Desta forma, são necessários os instrumentos urbanísticos, como as leis, para minimizar este processo que foi construído ao longo do tempo. Assim, este estudo pautou-se em algumas reflexões acerca dos aspectos de urbanização, planejamento e infraestrutura dos centros urbanos.
\end{abstract}

Palavras-chave: Cidade; Planejamento; Meio ambiente; Aspectos sociais.

\begin{abstract}
The growing urban development constantly presents (re) formulations that contain the complex process of physical and population structure that exist in a certain city, characterizing the urban space, which is the place of these social and environmental relations that are part of the entire urban infrastructure. The basis for any deployment of a new city must start from a good urban planning, taking into account not only the structural aspects of the new urban center, but also political, historical and economic factors. In this sense, urban infrastructure networks make the connection between all these aspects that composes life in society. Among these forms are some suggestions of implementations such as the green infrastructure, which takes as relevant aspects the natural environment as ways of providing better living conditions. It is also found the socio-spatial processes, from urban segregation, where the less favored classes are isolated in a certain region of the city. In this way, urbanistic instruments, such as laws, are needed to minimize this process that has been built up over time. Thus, this study was based on some reflections about urbanization, planning and infrastructure aspects of urban centers.
\end{abstract}

Keywords: City; Planning; Environment; Social aspects.

Resumen

El creciente desarrollo urbano presenta constantemente (re) formulaciones que abrigan el complejo proceso de estructuración física y poblacional que vive en determinada ciudad, caracterizando el espacio urbano, escenario de esas relaciones sociales y ambientales que forman parte de toda la infraestructura urbana. La base para cualquier implantación de una nueva ciudad debe partir de una buena planificación urbanística, que tenga en cuenta no sólo cómo los aspectos estructurales componen el nuevo centro urbano, sino también factores políticos, históricos y económicos. En este sentido, las redes de infraestructura urbana hacen la conexión entre todos estos aspectos que componen la vida en sociedad. Entre estas formas se encuentran algunas sugerencias de implementaciones como la infraestructura verde, que toma como aspecto relevante el ambiente natural como forma de propiciar mejores condiciones de vida, siendo también encontrado los procesos socioespaciales, provisto de segregación urbana, en que las clases menos favorecidas van quedando aisladas en determinada región de la ciudad. De esta forma, son necesarios los instrumentos urbanísticos, como las leyes, para minimizar este proceso que fue construido a lo largo del tiempo. Así, este estudio se basó en algunas reflexiones acerca de los aspectos de urbanización, planificación e infraestructura de los centros urbanos.

Palabras clave: Ciudad; Planificación; Medio ambiente; Aspectos sociales. 


\section{INTRODUÇÃO}

A expansão urbana tem crescido significativamente desde o início do século XVIII com a Revolução Industrial. O processo de fortalecimento do setor fabril e a seca em muitas regiões gerou na população do campo perspectivas de que nos centros urbanos as condições de vida seriam melhores, levando-os a migrar para as cidades, processo conhecido como êxodo rural (LIMA, 2015).

No Brasil, este fenômeno social teve seu início em meados do século XX, período em que aproximadamente 11 milhões de pessoas deixaram o campo para iniciar a vida na cidade, chegando a um montante de 30 milhões de pessoas até o final da década de 1970. Deste modo, pode-se afirmar que as cidades cresceram tanto em espaço geográfico como demográfico (MUELLER; MARTINE, 1997; CAMARANO; ABRAMOVAY, 1998), trazendo consequências variadas para o meio ambiente e para sociedade Foi necessária a adequação dos espaços físicos, objetivando fornecer uma infraestrutura mínima para a população, propor soluções que visem a gestão destes espaços que em vários casos foram crescendo de forma desordenada, não levando em consideração o processo social, cultural, histórico e ambiental do local urbanizado (OLIVEIRA; FLECK; BECKER, 2011).

Neste sentido, o ambiente urbano com estrutura inadequada pode apresentar diversas características peculiares que ocasionam consequências ao bem-estar e desenvolvimento da sociedade quando não há planejamento, como por exemplo a ineficiência nos modais de transportes, excepcionalmente os coletivos públicos, as precárias estruturas e falta de condições para moradia, saneamento, a falta de distribuição de energia elétrica, degradação do ambiente urbano. Ainda, o ambiente urbano pode apresentar as injustiças sociais, como o aumento da marginalidade, violência, negligência, segregação geográfica e as dificuldades de atender a população das áreas periféricas com serviços públicos básicos, sendo estas a realidade de muitas cidades brasileiras (MOREIRA, 1999; MARICATO, 2006, BICHIR, 2009; CORRÊA, 1995).

Segundo Farias Filho (2012), no Brasil, conjecturas de políticas públicas no universo urbano visam o aperfeiçoamento dos mecanismos de planejamento e gestão municipal, que levam a responsabilidades específicas devido à racionalização dos recursos públicos e a qualidade, eficiência e relevância de programas e projetos voltados para um melhor planejamento da urbanização.

Desta forma, faz-se importante o uso de dispositivos legais a fim de regulamentar e mitigar os problemas socioambientais, como, por exemplo, os impactos decorrentes de ocupações urbanas desenfreadas, sem planejamento da cidade, um desafio constante para a sociedade contemporânea. É imprescindível o estabelecimento de critérios que visem a implantação de um sistema de 
empreendimentos e atividades urbanas que possam alterar o espaço geográfico de forma menos impactante.

Em meio a tal necessidade de formulação de regras, em 10 de julho de 2001 foram estabelecidas as diretrizes gerais da política urbana Lei $\mathrm{n}^{\circ} 10.257 / 2001$, sendo que no Artigo $2^{\circ}$, inciso I é estipulado que "O direito às cidades sustentáveis compreende o direito à terra urbana, à moradia, ao saneamento ambiental, à infraestrutura urbana, ao transporte e aos serviços públicos, ao trabalho e ao lazer, para as presentes e futuras gerações" (BRASIL, 2001). Vizzotto e Prestes (2009, p. 36) ressaltam que as regras são importantes para

[...] ordenar a cidade, mas também garantir a preservação do ambiente urbano como um bem único e coletivo, não mais individual. As funções ambientais de participação democrática dos cidadãos, do desenvolvimento de ações para a implementação do direito à moradia, do aproveitamento adequado do solo urbano, entre outros, integram as funções sociais da cidade identificadas e que devem orientar a execução da política urbana.

Diante da prática global de democratizar a vida social e a paisagem urbana, este estudo tem como objetivo abordar algumas reflexões das relações que são estabelecidas entre o planejamento urbano, a biodiversidade e o desenvolvimento de redes de infraestrutura urbana.

\section{ESPAÇO URBANO}

A identidade da urbanização está relacionada à necessidade de agrupamentos de pessoas com o mesmo objetivo e o domínio que exercem sobre o arranjo espacial, como as aldeias que são subsequência das cidades-estados no período greco-romano, as cidades renascentistas com as suas preocupações geométricas e a harmonização das proporções e aparência (ABIKO et al., 1995). Ao referir-se a tal assunto, Castelnou (2007, p. 05) ressalta que:

Desde a Antiguidade, o homem viu o ESPAÇO URBANO [sic] como campo de intervenção, projetando cidades novas ou ainda fazendo modificações nos traçados das antigas. Porém, tais experiências eram fundamentadas somente em questões técnicas e estéticas, sem terem uma visão social, política e econômica ao se abordar o fenômeno.

Em contrapartida, a organização espacial urbana contemporânea decorre não apenas da visão técnica estrutural das cidades, mas também das influências entre as relações sociais, econômicas, políticas e culturais, caracterizando-o como produto das estratificações sociais ocasionadas pelo sistema econômico adotado, bem como os valores, crenças e mitos que fazem parte do contexto social e assim ditam regras de convívio e de organizações físicas como: monumentos, lugares sagrados, ruas especiais, 
entre outros (CORRÊA, 1995). Carlos (2007, p. 11) corrobora com esta percepção ao afirmar que "A cidade, enquanto construção humana, é um produto histórico-social e nesta dimensão aparece como trabalho materializado, acumulado ao longo do processo histórico de uma série de gerações”.

Desta forma, são constantes as evoluções nas cidades no período moderno, que tendem a se adaptar às novas necessidades, como, por exemplo, as cidades que implantaram novos centros cívicos, novos loteamentos ou até as cidades que transformam ruas em avenidas devido ao aumento do tráfego de veículos e pessoas. Castelnou (2007, p. 78) ressalta que "o desenvolvimento urbano de cada cidade depende das suas características geográficas, potencialidades econômicas e situação política e social". Neste sentido, a complexidade da temática urbana "procura entender e solucionar os problemas urbanos" (ABIKO et al., 1995, p. 39) oriundos das relações humanas e da natureza espacial.

Em meios às necessidades de atender as complexas relações que se propagam no meio urbano, tendo em vista a diversidade de relações sociais que estão alocadas em um mesmo espaço geográfico, o Planejamento Urbano e o Desenho Urbano podem auxiliar neste processo de proposição de soluções para determinada cidade, tendo em vista que o primeiro contribui para o arranjo das várias facetas que a mesma possui, levando em conta a historicidade, a economia, os aspectos psicológicos e tecnológicos, entre outros. A configuração dos projetos, com o formato e traçado que a cidade poderá tomar, fica a cargo do Desenho Urbano (CASTELNOU, 2007).

Para a concepção do planejamento urbano, é primordial a ligação entre as esferas públicas e privadas, "baseada na multidisciplinaridade de saberes, que passou a fundamentar quaisquer intervenções sobre a cidade desde então" (CASTELNOU, 2007, p. 99). Os governantes, tidos como representantes dos interesses da população, devem atuar como agentes modeladores para a estruturação do município. A este respeito, Abiko et al. (1995, p.46) ressalta:

A cidade enquanto empreendimento deverá satisfazer às necessidades individuais e coletivas dos vários setores de sua população; para tanto deve-se articular recursos humanos, financeiros, institucionais, políticos e naturais para sua produção, funcionamento e manutenção. A este processo dirigido para operar a cidade, dá-se o nome de gestão urbana.

Para atender o compromisso das cidades com a sociedade, a Constituição Federal de 1988 no Artigo 182, o Estatuto da Cidade de 2001 (lei federal de n. ${ }^{\circ}$ 10.257) e o Ministério das Cidades de 2003, garantem aos municípios a competência para conduzir programas em direção do desenvolvimento e crescimento sustentável, devendo criar e seguir as diretrizes previamente planejadas e estabelecidas no Plano Diretor, com o objetivo de dar um norte, direcionando para as questões sociais, econômicas e ambientais (CONTI; FARIA; TIMÓTEO, 2014). 
Segundo Rodrigues (2006), o Estatuto da Cidade dispõe sobre a obrigação de consolidar a função social dos centros urbanos, atribuindo aos Órgãos Públicos o papel de fiscalizar as ações imobiliárias nas cidades, de forma a assegurar a qualidade dos empreendimentos, seja pela implementação da infraestrutura, serviços urbanos, conforto mínimo que precisa ser assegurado, preservação e a harmonia visual, devendo também garantir a disponibilização de investimentos para o desenvolvimento estruturado nas áreas habitacionais mais afastadas, tidas normalmente como de baixa renda.

A cidade de Belém traz em seu plano diretor um exemplo da preocupação do legislador em buscar a otimização dos investimentos públicos, por meio da aquisição imobiliária, nas áreas onde a infraestrutura não tem explorado seu potencial máximo, em conformidade a um modelo estipulado por Lei (BELÉM, 1993).

\section{BIODIVERSIDADE URBANA}

O dinamismo da cidade é caracterizado pelo ecossistema urbano, que se configura por meio da relação concomitante entre os seres vivos e o ambiente. Desta forma, a organização espacial pode ser compreendida como uma construção humana realizada por meio de objeto ou formas espaciais ao longo da história (CORRÊA, 1995). Ávila (2011) ressalta que a cidade é a expressão viva da identidade de um povo a qual foi moldada, retratando por meio de sinais físicos, como: sua localização, as marcas da cultura de uma sociedade, transmitindo às próximas gerações suas memórias coletivas.

Neste sentido, para melhor atender a população em suas necessidades sociais, econômicas, políticas, culturais entre outras, é importante produzir um arranjo espacial por meio de estratégias de planejamentos e sistemas urbanos (CASTELNOU, 2007). Abiko et al. (1995) já havia ressaltado esta mesma consideração, ao afirmar que em meio ao desenvolvimento urbano surgiu a necessidade da ação pública para ordenar e propor soluções que até então eram regidas pelo setor privado, cujos objetivos não atendem a uma coletividade e os prazos estipulados são mínimos.

O Estado atua de forma complexa e variável em diferentes outros aspectos das configurações espaciais arquitetônicas das cidades, propondo e traçando projetos de infraestruturas por meio de conhecimentos técnicos e de forma estratégica na elaboração de áreas urbanas (CORRÊA, 1995).

Ao se abordar biodiversidade urbana, pode-se compreender que seus aspectos peculiares estão interligados conforme as necessidades, e são atendidos por meio de uma rede de infraestruturas conectadas, conhecida como cidade. O planejamento urbano deve se conectar com os espaços de forma a atender aspectos sociais, econômicos, ambientais e habitacional que compõem toda a vida em sociedade, 
logo sua função é de integração (ABIKO et al., 1995; CASTELNOU, 2007; MOREIRA, 1999; FERREIRA; LEITE, 2011; BERTEI, 2014; LIMA, SIMÕES; MONTE-MÓR, 2014).

Ao pensar em infraestrutura, é primordial contemplar os serviços básicos que envolvem a vida urbana (BERTEI et al., 2014), e que são consolidados por meio de redes de infraestrutura projetadas para melhor atender as necessidades da população e do ambiente como um todo.

\section{REDES DE INFRAESTRUTURA URBANA}

\section{SISTEMAS URBANÍSTICOS TÉCNICOS}

A origem das redes de infraestrutura urbana são tão antigas quanto as próprias cidades, datando desde a construção das primeiras redes viárias dos calçamentos romanos até chegar aos vários tipos de pavimentos que hoje podem ser encontrados. Ao pensarmos na organização estrutural que atualmente estão presentes nas cidades, podemos defini-la como nos deparamos com uma imensidade de infraestruturas que fazem parte do fornecimento de serviços básicos, como: água, esgoto, transporte, fornecimento de energia elétrica, entre outros que circulam entre as aglomerações e atualmente imprescindíveis para o contexto atual de desenvolvimento de várias atividades do cotidiano, as quais realizamos sem nos dar conta do quanto estes serviços são essenciais, por já estarmos acostumados a utilizá-los (BERTEI et al., 2014; SANTOS, 2005).

A engenharia urbana responsável por todo o planejamento e construção das infraestruturas que atendem as cidades, pode ser explicada por meio de dois sentidos: rede suporte relacionando-se à dimensão física do espaço urbano; e às redes de serviços, caracterizadas por demandar atendimento às necessidades da cidade. A união destes dois significados reflete o caráter técnico presente nas atividades de construção de uma infraestrutura urbana. Conforme Bertei et al. (2014, p. 304), "a engenharia urbana é a arte de conceber, realizar e gerenciar sistemas técnicos".

Utilizando-se dos sistemas técnicos, a implementação das redes de projetos de planejamento urbano, as redes de infraestrutura como o sistema sanitário, abastecimento de água, tratamento de esgoto e coleta de resíduos, escoamento superficial, atendimento às demandas energéticas e de telecomunicações e os sistemas modais estão conectados uns aos outros para atender as demandas e desenvolvimento social e tecnológico (ABIKO et al., 1995; CORRÊA, 1995; MOREIRA, 1999).

Desta forma, a urbanização e o aprimoramento das redes de infraestrutura estabelece um processo com alto potencial de desenvolvimento, mas também é preciso pensar nos desafios que serão gerados com o crescimento das cidades, como por exemplo a diminuição das terras para cultivo e a quantidade de pessoas que precisam ser alocadas de forma ordenada nestas cidades (BRASIL, 2012). 


\section{INSTRUMENTOS URBANÍSTICOS: INFRAESTRUTURA VERDE}

Com o desenvolvimento e a modernização das cidades, a busca por novas redes de infraestrutura urbana que atendam as necessidades sociais e ambientais tem aumentado entre os estudiosos de instrumentos urbanísticos. Dentre eles destaca-se a infraestrutura verde, também conhecida como infraestrutura ecológica (YU; PADUA, 2006; IGNATIEVA, 2010), desenvolvida após o reconhecimento dos benefícios que a natureza pode oferecer à cidade contribuindo para que os projetos urbanísticos sejam desenvolvidos dando ênfase aos aspectos sociais e ambientais (CORMIER; PELLEGRINO, 2008).

Ainda segundo os autores, este tipo de infraestrutura não é simplesmente uma maneira de embelezar a cidade, mas promover acessibilidade e unir o homem ao espaço, com obras de artes arquitetônicas e de engenharia, de maneira a exercer o manejo urbano tal qual, as boulevard, paisagismo, áreas verdes (praça, parque e reservas ambientais) e integração com estas áreas de lazer, proporcionado melhor qualidade de vida e a valorização econômica e social do espaço.

A infraestrutura verde também tem como preocupação a união dos aspectos urbanos e ambientais, de modo que adotem tecnologias práticas, que se adaptem aos projetos das cidades, proporcionando menor consumo de energia, diminuição na emissão de gases de efeito estufa, evitando a sedimentação de rios e lagos, protegendo e aumentando a biodiversidade, diminuindo a poluição das águas, do ar e do solo, integrando os modais, acessibilidades, saneamento ao bem-estar ambiental, processo e ciclos naturais, e a identificação de um povo por meio da cidade (CORMIER; PELLEGRINO, 2008; HERZOG; ROSA, 2010).

Um dos exemplos de execução e utilização da infraestrutura verde é a cidade de Freiburg no sul da Alemanha, onde foi construído uma conexão ao lado do rio para ciclistas e pedestres ao longo de 9,5 quilômetros de extensão urbana. Para sua construção foram utilizadas duas escalas: a urbana e a local. A escala urbana é caracterizada por uma rede de conservação de áreas agrícolas que permeiam a cidade, e na escala local é realizado um trabalho com os proprietários para preservar e integrar o plano com a paisagem (HERZOG; ROSA, 2010).

Outro exemplo, ocorre nos Estados Unidos, em Washington e Oregon, e na Província da Colúmbia Britânica, no Canadá, em que a infraestrutura verde é compreendida como uma forma de adaptar as paisagens urbanas às funções ecológicas e hidrológicas da natureza (CORMIER; PELLEGRINO, 2008).

No Brasil há também um projeto desenvolvido pelo Instituto de Pesquisas em Infraestrutura Verde e Ecologia Urbana (INVERDE), para a bacia hidrográfica urbana da cidade do Rio de Janeiro, 
apresentando várias propostas de melhorias para a biodiversidade, a qualidade das águas, transportes público alternativos como "bicicletas e pedestres, infiltração e detenção das águas das chuvas ao longo da bacia; filtragem das águas antes de entrar no sistema de águas pluviais"; "aumentar a biodiversidade nativa; educar e dar visibilidade aos processos naturais e ecossistemas nativos, entre outros" (HERZOG; ROSA, 2010, p. 111).

Tendo em vista as possibilidades de melhoria do bem estar social e ambiental com a implantação de projetos urbanísticos como a infraestrutura verde, faz-se importante pensar no desenvolvimento e execução de novos projetos urbanos que permeiam não apenas a estrutura física da cidade, mas também que leve em conta as transformações benéficas que este tipo de projeção urbanístico pode causar em toda a sociedade ao modificar a paisagem predominantemente urbana em espaços que se relacionem com a natureza do local.

\section{PROCESSOS SOCIOESPACIAIS DA INFRAESTRUTURA URBANA}

Os processos espaciais urbanos entendidos como atividade prática estão relacionados à forma como as relações sociais se desenvolvem, levando em conta a realização humana ao se apropriar de um determinado local (CARLOS, 2007).

Nesta perspectiva, o espaço urbano é caracterizado pelos aspectos sociais estabelecidos na sociedade, dentre eles o socioeconômico, o qual no sistema capitalista versa principalmente sobre o poder de compra de um indivíduo.

Desta forma, segundo Ferreira e Leite (2011), o processo de produção espacial de uma cidade está diretamente ligado às condições socioeconômicas e consequentemente as modificações que são geradas, como as alterações no preço do mercado imobiliário, corrobora com a segregação socioespacial. Segundo Villaça (1998, p. 142), “a segregação é um processo segundo o qual diferentes classes ou camadas sociais tendem a se concentrar cada vez mais em regiões gerais ou conjunto de bairros [...]”. Neste contexto, pode-se afirmar que

As atuais configurações espaciais e sociais na cidade, que estão sujeitas a um momento de forte diferenciação, com a existência de rupturas entre os vários grupos sociais, organizações e territórios urbanos, evidenciam os processos de segregação, perceptíveis na proliferação dos novos estilos de morar e de (con)viver no espaço urbano (FERREIRA; LEITE, 2011, p. 13).

Em meio a estas segregações espaciais surgem diferentes espaços dentro de uma mesma cidade, sendo algumas providas de serviços que promovem bem estar social, onde residem a população mais privilegiada do setor econômico e um outro estrato da cidade que vivencia constantemente a falta de 
infraestrutura básica para as necessidades de sobrevivência humana, como por exemplo a população que reside em cortiços, favelas, praças e ruas dos centros urbanos (MARQUES; BICHIR, 2001; CARLOS, 2007; FERREIRA; LEITE, 2011).

$\mathrm{Na}$ busca de soluções para esta problemática da segregação socioespacial, os instrumentos urbanísticos que "constituem princípios básicos e fundamentais para idealizar o Planejamento urbano" (FERREIRA; LEITE, 2011, p. 16), os quais constituem-se das Leis urbanas. Os Órgãos Públicos e a sociedade precisam procurar por meio de políticas econômicas e sociais reconfigurar o modo de produção, o que consequentemente poderá contribuir para uma nova estrutura do espaço e então viabilizar a diminuição da segregação socioespacial, além de precisar ser incorporado ao processo de reconfiguração a dissolução de antigas relações e a geração de outras novas. No entanto, sabe-se que este não é um processo realizado sem levar em conta os fatores históricos que influenciaram a constituição da sociedade como está estruturada (LIMA; SIMÕES; MONTE-MÓR, 2014).

\section{CONSIDERAÇÕES FINAIS}

Devido ao crescente desenvolvimento urbano se faz necessário planejar os espaços de modo a democratizar a cidade e fornecer à população redes de infraestruturas que atendam as necessidades mínimas de modo a organizar a sociedade e o espaço físico para a população, minimizando os impactos gerados na cidade e no meio ambiente.

Deste modo, o planejamento urbano deve ser realizado levando em conta aspectos sociais como o processo histórico, econômico e cultural da cidade, sem privilegiar determinadas regiões, minimizando assim a segregação socioespacial.

Sob efeito de fim, o espaço urbano deve ser aprimorado, condicionando seu desenvolvimento por meio da legislação urbanística, que visa fornecer organização para o atendimento de serviços públicos e infraestrutura mínima para a população.

\section{Referências}

ABIKO, A. K.; ALMEIDA, M. A. P. de; BARREIROS, M. A. F., Urbanismo: História e Desenvolvimento. Escola Politécnica Da Universidade De São Paulo Departamento De Engenharia De Construção Civil. São Paulo - SP, 1995. Acesso: 24 de maio de 2017. Disponível em: <http://reverbe.net/cidades/wpcontent/uploads/2011/08/urbanismohistoriaedesenvolvimento.pdf >. Acesso em: 27 de julho. 2017.

ÁVILA, S. X. A Cidade como Personagem no Cinema. 2011. Dissertação (Mestrado em Arquitectura com especialização em Planeamento Urbano e Territorial) Faculdade de Arquitectura, Universidade Técnica de Lisboa, Lisboa, 2011. Disponível em:

<http://www.repository.utl.pt/bitstream/10400.5/3705/1/D ocumento\%20Final.pdf>. Acesso em: 27 de julho. 2017.

BELÉM (PA). Lei 7603/93 de 13 de janeiro de 1993. Dispõe sobre o plano diretor do município de Belém e dá outras providências. Disponível em: $<$ https://cmbelem.jusbrasil.com.br/legislacao/585164/lei-760393\#art-143>. Acesso em 30 de julho de 2017. Acesso em: 26 de julh. 2017. 
BERTEI, R. M.; PANDOLFO, A.; BARBACOVI, N. E.; MORO, L. D.; GOMES, A. P.; MORO, P. D.; BERTICELLI, R.; TAGLIARI, L. D.; PANDOLFO, L. M. Desenvolvimento de um Sistema de Informação para o Gerenciamento de Redes de Infraestrutura Urbana. Revista de Administração IMED - RAIMED, Passo Fundo - RS, v. 4, n. 3, p. 300-313, set/dez, 2014.

BRASIL. Panorama da biodiversidade nas cidades: ações e políticas. Ministério do Meio Ambiente, 2012. Disponível em:

file:///C:/Users/Kairo/Downloads/livro_panorama\%20das $\%$ 20cidades_web-1.pdf.

CAMARANO, A. A.; ABRAMOVAY, R. Êxodo rural, envelhecimento e masculinização no Brasil: panorama dos últimos cinquenta anos. Revista Brasileira de Estudos de População, Brasília, v. 15, n. 2, p. 45-64, 1998. Disponível em:

<http://www.abep.nepo.unicamp.br/docs/rev_inf/vol15_n 2_1998/vol15_n2_1998_4artigo_45_65.pdf > Acesso em: 25 de julh. 2017.

CARLOS, A. F. A. O espaço urbano: novos escritos sobre a cidade. São Paulo: USP, 2007. Disponível em: $<$

http://gesp.fflch.usp.br/sites/gesp.fflch.usp.br/files/Espaco urbano.pdf >. Acesso em: 31 de julh. 2017.

CARONE, I. Psicanálise fim de século. Ensaios críticos. São Paulo: Hacker, 1998. Resenha de: FRAYZEPEREIRA, J. A. Da possibilidade da crítica à cultura: psicanálise e filosofia. Revista Brasileira de Psicanálise, v. 35, n. 2, p. 403-405, 2001.

CASTELnOU, A. Teoria do Urbanismo. Universidade Federal do Paraná - Arquitetura e Urbanismo. CuritibaPR, 2007.

CONTI, E. F.; FARIA, T. P.; TIMÓTEO, G. M. Os vazios urbanos versus a função social da propriedade: o papel do plano diretor da cidade de Campos dos Goytacazes.

Boletim de Geografia, Maringá, v. 32, n. 3, p. 151-169, set.-dez. 2014. Disponível em:

<http://www.periodicos.uem.br/ojs/index.php/BolGeogr/a rticle/viewFile/20379/pdf 37>. Acesso em: 27 de julh. 2017.

CORMIER, N. S.; PELEGRINO, P. R. M. Infra-estrutura Verde: Uma Estratégia Paisagística para a Água Urbana. Revista Paisagem Ambiental, São Paulo - SP, Ensaion.25, p. 125-142, 2008.

CORRÊA, R. L. O Espaço Urbano. Editora Ática, Série Princípios, 1995.

FERREIRA, M.R.; LEITE, M. E. Instrumentos Urbanísticos e Tecnológicos na Análise dos Processos Socioespaciais Urbano. Revista Caminhos de Geografia, Uberlândia - MG, v. 12, n. 40, p. 12-25, dez, 2011.
HERZOG, C. P.; ROSA, L. Z. Infraestrutura verde: sustentabilidade e resiliência para a paisagem urbana. Revista LABVERDE, São Paulo - SP, v. 1, p. 1-24, 2010.

IGNATIEVA, M. Planning and design of ecological networks in urban areas. In: Proceedings of teh 2 nd International Conference of Urban Biodiversity and Desing. Nagoya, Japão, 18-22 de maio de 2010. pp.24-26.

LIMA, R. P. As causas e consequências do fluxo migratório do povoado Brasília. Revista Eletrônica da Faculdade José Augusto Vieira, v. 8, n. 9, nov. 2015. Disponível em: <http://fjav.com.br/revista/Downloads/EdicaoAnoVIIIVol 8n9/Artigo11.pdf>. Acesso em: 24 de julh. 2017.

LIMA, A. C. C.; SIMÕES, R.; MONTE-MÓR, R. L. M. Espaço, cidades e escalas territoriais: novas implicações de políticas de desenvolvimento regional. Revista Economia e Sociedade, Campinas - SP, v. 23, n. 1, p. 223-242, abr, 2014.

MOREIRA, A. C. M. L. Parâmetros para elaboração do relatório de impacto de vizinhança. Revista do Programa de Pós-Graduação em Arquitetura e Urbanismo da FAUUSP, São Paulo, n. 7, p. 107-118, 1999. Disponível em:

$<$ http://lproweb.procempa.com.br/pmpa/prefpoa/spm/usu doc/moreira a c. -

_parametros_para_elaboracao_do_riv.pdf >. Acesso em: 27 de julh. 2017.

MUELLER, C. C.; MARTINE, G. Modernização da agropecuária, emprego agrícola e êxodo rural no Brasildécada de 1980. Brasília, 1997. Disponível em: < http://www.rep.org.br/pdf/67-7.pdf > Acesso em: 24 de jun. 2011.

OLIVEIRA, E.; FLECK, L.; BECKER, M. Êxodo rural e sua problemática em relação ao meio ambiente e sociedade civil. In.: I Seminário Internacional do Espaços de Fronteira, III Seminário Regional sobre Território, Fronteira e Cultura, VII Expedição Geográfica da Unioeste: espaços de Fronteira - Território e Ambiente, Universidade Estadual do Oeste do Paraná, Campus Rondon, setembro 2011.

RODRIGUES, A. S. A organização do espaço urbano e a gestão da cidade. In.:

Revisão do Plano Diretor do Município de Belém.

Disponível em:

<http://www.belem.pa.gov.br/planodiretor/pdfs/Artigos.pd f>. Acesso em: 3023 de julh. 2017.

SANTOS, M. Da Totalidade ao Lugar. São Paulo: EDUSP, 2005.

VIZZOTTO, A. T.; PRESTES, V. B. Direito urbanístico. Porto Alegre: Verbo Jurídico, 2009. 
YU, K.; PADUA, M. The Art of Survival: Recovering Landscape Architecture. The Images Publishing Group Pty, Victoria,

2006. 
Recebido em: 31/07/2017

Aceito em: 26/10/2017

Endereço para correspondência:

Nome: Gunar Henrique Guedes

(c) (7)

Email: gunnarguedes@gmail.com

Esta obra está licenciada com uma Licença $\underline{\text { Creative }}$

Commons Atribuição 4.0 Internacional. 